\title{
Impact of neutrophil-to-lymphocyte ratio on effects of targeted therapy for metastatic renal cell carcinoma patients with extrapulmonary metastasis
}

\author{
Jun Teishima, $M D^{\prime}$; Shinya Ohara, $M D^{2}$; Kousuke Sadahide, $M D^{\prime}$; Shinsuke Fujii, MD'; Hiroyuki Kitano, MD'; \\ Kohei Kobatake, MD'; Shunsuke Shinmei, MD'; Keisuke Hieda, MD'; Shogo Inoue, MD'; \\ Tetsutaro Hayashi, MD'; Koji Mita, MD²; Akio Matsubara, MD'
}

'Department of Urology, Institute of Biomedical and Health Sciences, Integrated Health Sciences, Hiroshima University; ${ }^{2}$ Department of Urology, Hiroshima-City Asa Citizens Hospital; Hiroshima, Japan

Cite as: Can Urol Assoc J 2017;11 (5):E207-14. http://dx.doi.org/10.5489/cuaj.4106 Published online May 9, 2017

\section{Abstract}

Introduction: The aim of our present study was to investigate the impact of the pretreatment neutrophil-to-lymphocyte ratio (NLR) on the antitumour effects of targeted agents in patients with metastatic renal cell carcinoma (mRCC).

Methods: The NLRs in 283 cases of molecular targeted therapy for $\mathrm{mRCC}$ were measured before starting the prescription of the molecular targeted agent. The significance of pretreatment NLR on the site of metastatic organs and on progression-free survival (PFS) in each case was analyzed.

Results: Metastases other than lung, which is defined as "extrapulmonary metastasis," were observed in 190 cases (67.1\%). The median of pretreated NLR was 2.39 (0.49-68.7). In 97 of the 283 cases, pretreated NLR was 3.0 or higher. These cases were categorized as the high NLR group and the rest as the low NLR group. When the cases with extrapulmonary metastasis were investigated and classified based on their pretreated NLR, 50\% PFS in the high NLR and low NLR groups was 6.7 months and 12 months ( $p=0.0001)$, respectively. Multivariate analysis revealed that high NLR (>3.0) was an independent predictive factor for PFS in the cases with extrapulmonary metastasis (hazard ratio 2.762; $\mathrm{p}<0.0001$ ), while there was no significant difference between PFS in the high and low NLR groups in cases with no extrapulmonary metastasis $(p=0.3457)$.

Conclusions: Our data indicate that the predictive significance of the NLR in mRCC cases involving targeted therapy depends on the metastatic organs. NLR is an independent predictive factor of PFS in cases of mRCC with extrapulmonary metastasis treated with targeted therapy.

\section{Introduction}

Renal cell carcinoma (RCC) is the third most common malignant disease in genitourinary organs, and 30\% of RCC patients have metastases at initial diagnosis. ${ }^{1}$ Molecular targeted therapies have recently become standard options in the treatment for metastatic RCC (mRCC) through randomized, control trials reporting the efficacy of targeted agents. ${ }^{2-7}$ Due to the rapid spread of such therapy, clinicians have recognized the difference in clinical outcomes of targeted therapy in each case. Therefore, it has been important to identify novel biomarkers for predicting the effects of targeted agents for mRCC.

It is well-known that systemic inflammatory response plays an important role in the development and progression of several malignant diseases. ${ }^{8,9}$ Parameters of inflammatory response, such as C-reactive protein (CRP), have been reported as prognostic markers in urological cancers. ${ }^{10-12}$ The implication of CRP for predicting the prognosis or the effect of agents has also been demonstrated with targeted therapy in RCC. ${ }^{13}$

Besides CRP, the elevation of the neutrophils-to-lymphocytes ratio (NLR) has been reported as a prognostic factor in cancers, including RCC. ${ }^{14}$ Although various studies have shown the association between high NLR and poor prognosis of RCC, ${ }^{14,15}$ there has been no report on determining the impact of the NLR on the effects of targeted agents regarding metastatic organ status. We therefore investigated the impact of pretreatment NLR on the effect of molecular targeted therapy for mRCC by focusing on the site of metastatic organs.

\section{Methods}

The study was approved by the Ethics Committee of Hiroshima University (Hiroshima, Japan). Two hundred eighty-three cases of molecular targeted therapy for mRCC at our institute and other hospitals in Hiroshima Prefecture from 2007-2015 whose clinical and pathological information have been clarified were included in this study. Neutrophils and lymphocytes were measured within 14 days prior to starting the prescription of molecular targeted agents and when computed tomography (CT) scan was conducted in order to elucidate its effect. We chose three as a threshold value of pretreatment NLR based on the previous 
Teishima et al.

report. ${ }^{15}$ Cases for which the pretreatment NLR was three or higher and the others were classified into high and low NLR groups, respectively.

All cases were further classified according to age, gender, histological finding, performance status, anemia, serum calcium, lactate dehydrogenase $(\mathrm{LDH})$, pretreatment serum CRP, metastatic organs, prior nephrectomy, choice of drug, and timing of treatment. Metastases other than lung were defined as extrapulmonary metastasis. The distribution of each subgroup in the high and low NLR groups and their progression-free survival (PFS) were compared.

The differences in the distribution of variables among the groups were analyzed using the chi-square test for categorical variables and Mann-Whitney test for continuous variables. The PFS was determined using the Kaplan-Meier method and analyzed using log-rank testing. The relationship between the variables and PFS was examined using the Cox proportional hazard model. Variables with $p$ values less than 0.05 on univariate analysis were included in the multivariate analysis. All statistical analyses were conducted using the JMP 10.0.0 (SAS Institute Inc., NC, U.S), and $p$ values less than 0.05 were considered to be statistically significant.

\section{Results}

This study cohort consisted of 283 cases of molecular targeted therapy for mRCC. The characteristics of the cases are listed in Table 1. One hundred eighty-six (65.7\%) cases and $97(34.3 \%)$ cases were categorized as low and high NLR groups, respectively. Of all cases pathologically diagnosed as RCC, 255 cases were performed prior nephrectomy, which included 116 cytoreductive nephrectomies and 139 radical ones. Median of time from surgery to the start of targeted therapy was 24.7 (3-239) months in cases of radical nephrectomy. The rates of cases of 1 or higher Eastern Cooperative Oncology Group (ECOG)-performance status (PS) score, anemia, hypercalcemia, higher CRP, high LDH, or without prior nephrectomy in the high NLR group were significantly higher than those in the low NLR group.

The PFS curve for the entire cohort is shown in Fig. 1. Disease progression was shown in 125 of 253 cases. The $50 \%$ PFS for the entire cohort was 11 months. When they were classified into low and high NLR groups, the 50\%PFS for the low NLR group (12 months) was significantly better than that for the high NLR group (eight months, $\mathrm{p}=0.0015$ ) (Fig. 2). Univariate analyses revealed that several variables were significantly associated with PFS, including histological findings, PS, anemia, hypercalcemia, prior nephrectomy, number of metastatic organs, timing of treatments, and pretreated NLR. Multivariate analyses revealed that pretreated NLR, as well as the histological findings, PS, and timing of treatment were independent prognostic factors for PFS (Table 2).

While there was no significant difference in the distribution of lung metastasis between the low and high NLR

\begin{tabular}{|c|c|c|c|c|}
\hline & \multicolumn{2}{|c|}{ Pretreated NLR } & \multirow[b]{2}{*}{$\mathbf{p}$} & \multirow[t]{2}{*}{ Total } \\
\hline & $\begin{array}{l}\text { Low } \\
(\leq 3.0)\end{array}$ & $\begin{array}{l}\text { High } \\
(>3.0)\end{array}$ & & \\
\hline No. of patients & 186 & 97 & & 283 \\
\hline Age range (median) & $4-85(65)$ & $44-85(66)$ & 0.6284 & $40-85(65)$ \\
\hline \multicolumn{5}{|l|}{ Gender, n (\%) } \\
\hline Male & $148(79.6)$ & $82(84.5)$ & 0.3094 & $230(81.3)$ \\
\hline Female & $38(20.4)$ & $15(15.5)$ & & $53(18.7)$ \\
\hline \multicolumn{5}{|l|}{$\begin{array}{l}\text { Histological type, n } \\
\text { (\%) }\end{array}$} \\
\hline Clear & $165(88.7)$ & $83(85.6)$ & 0.4459 & $253(89.4)$ \\
\hline Non-clear & $21(11.3)$ & $14(14.4)$ & & $35(12.4)$ \\
\hline \multicolumn{5}{|l|}{$\begin{array}{l}\text { ECOG performance } \\
\text { status, } n(\%)\end{array}$} \\
\hline 0 & $160(86.0)$ & $71(73.2)$ & 0.0082 & $231(81.6)$ \\
\hline$\geq 1$ & $26(14.0)$ & $26(26.8)$ & & $52(18.4)$ \\
\hline \multicolumn{5}{|l|}{ Anemia, n (\%) } \\
\hline$(-)$ & $95(51.1)$ & $28(28.9)$ & 0.0003 & $123(43.5)$ \\
\hline$(+)$ & $91(48.9)$ & $69(71.1)$ & & $160(56.5)$ \\
\hline \multicolumn{5}{|l|}{ Hypercalcemia, n (\%) } \\
\hline$(-)$ & $184(98.9)$ & 89 (91.8) & 0.0438 & $273(96.5)$ \\
\hline$(+)$ & $2(1.1)$ & $8(8.2)$ & & $10(3.5)$ \\
\hline \multicolumn{5}{|l|}{ LDH, n (\%) } \\
\hline$\leq 1.5 \times$ ULN & $179(96.2)$ & $87(89.7)$ & 0.0278 & $266(4.0)$ \\
\hline$>1.5 \times$ ULN & $7(3.8)$ & $10(10.3)$ & & $17(6.0)$ \\
\hline \multicolumn{5}{|l|}{ Pretreated CRP, n (\%) } \\
\hline$<0.3 \mathrm{mg} / \mathrm{dL}$ & $113(60.8)$ & $25(25.8)$ & $<0.0001$ & $138(48.8)$ \\
\hline$\geq 0.3 \mathrm{mg} / \mathrm{dL}$ & $73(39.2)$ & $72(74.2)$ & & $145(51.2)$ \\
\hline \multicolumn{5}{|l|}{$\begin{array}{l}\text { Metastatic organs, } \\
\mathrm{n}(\%)\end{array}$} \\
\hline \multicolumn{5}{|l|}{ Lung } \\
\hline$(-)$ & $46(24.7)$ & 27 (27.8) & 0.5711 & 73 (25.8) \\
\hline$(+)$ & $140(75.3)$ & $70(72.2)$ & & $210(74.2)$ \\
\hline \multicolumn{5}{|l|}{ Liver } \\
\hline$(-)$ & 155 (83.3) & $83(85.6)$ & 0.6258 & 238 (84.1) \\
\hline$(+)$ & 31 (16.7) & $14(14.4)$ & & 45 (15.9) \\
\hline \multicolumn{5}{|l|}{ Bone } \\
\hline$(-)$ & $148(79.6)$ & 62 (63.9) & 0.0043 & $210(74.2)$ \\
\hline$(+)$ & $38(20.4)$ & $35(36.1)$ & & $73(25.8)$ \\
\hline \multicolumn{5}{|l|}{ Brain } \\
\hline$(-)$ & $182(97.8)$ & $88(90.7)$ & 0.0066 & 270 (95.4) \\
\hline$(+)$ & $4(2.2)$ & $9(9.3)$ & & $13(4.6)$ \\
\hline
\end{tabular}

groups, the rate of the cases with bone, brain, or extrapulmonary metastases in the high NLR group were significantly higher than that in the low NLR group (Table 1), suggesting that there might be some associations between metastatic status and the impact of NLR. Therefore, we focused on the cases with extrapulmonary metastasis. As shown in Table 3 , the rates of the anemia and hypercalcemia cases were significantly higher and that with prior nephrectomy was significantly lower than those in the low NLR group. In the 
NLR of mRCC in targeted therapy

\begin{tabular}{|c|c|c|c|c|}
\hline & \multicolumn{2}{|c|}{ Pretreated NLR } & \multirow[b]{2}{*}{$\mathbf{p}$} & Total \\
\hline & $\begin{array}{l}\text { Low } \\
(\leq 3.0)\end{array}$ & $\begin{array}{l}\text { High } \\
(>3.0)\end{array}$ & & \\
\hline \multicolumn{5}{|l|}{ Ipsilateral kidney } \\
\hline$(-)$ & $167(89.8)$ & 93 (95.9) & 0.0751 & 260 (91.9) \\
\hline$(+)$ & $19(10.2)$ & $4(4.1)$ & & $23(8.1)$ \\
\hline \multicolumn{5}{|l|}{ Adrenal gland } \\
\hline$(-)$ & $175(94.1)$ & 91 (93.8) & 0.9273 & $266(94.0)$ \\
\hline$(+)$ & $11(5.9)$ & $6(6.2)$ & & $17(6.0)$ \\
\hline \multicolumn{5}{|l|}{ Pancreas } \\
\hline$(-)$ & $176(94.6)$ & 93 (95.9) & 0.6446 & $269(95.0)$ \\
\hline$(+)$ & $10(5.4)$ & $4(4.1)$ & & $14(5.0)$ \\
\hline \multicolumn{5}{|l|}{ Soft tissue } \\
\hline$(-)$ & $170(91.4)$ & 89 (91.8) & 0.9190 & $259(91.5)$ \\
\hline$(+)$ & $16(8.6)$ & $8(8.2)$ & & $24(8.5)$ \\
\hline \multicolumn{5}{|l|}{ Lymph node } \\
\hline$(-)$ & $135(72.6)$ & $67(69.1)$ & 0.5354 & $202(71.4)$ \\
\hline$(+)$ & $51(27.4)$ & $30(30.9)$ & & $81(28.6)$ \\
\hline \multicolumn{5}{|l|}{$\begin{array}{l}\text { Extrapulmonary } \\
\text { metastasis, n (\%) }\end{array}$} \\
\hline$(-)$ & $75(40.3)$ & 18 (18.6) & 0.0002 & 93 (32.9) \\
\hline$(+)$ & $111(59.7)$ & 79 (81.4) & & $190(67.1)$ \\
\hline \multicolumn{5}{|l|}{$\begin{array}{l}\text { No. of metastatic } \\
\text { organs, } \mathrm{n}(\%)\end{array}$} \\
\hline 1 & $116(62.4)$ & $43(44.3)$ & 0.0037 & $159(56.2)$ \\
\hline$\geq 2$ & 70 (37.6) & $54(55.7)$ & & $124(43.8)$ \\
\hline \multicolumn{5}{|l|}{$\begin{array}{l}\text { Prior nephrectomy, n } \\
\text { (\%) }\end{array}$} \\
\hline Yes & $174(93.5)$ & $81(83.5)$ & 0.0072 & $255(90.1)$ \\
\hline No & $12(6.5)$ & 16 (16.5) & & $28(9.9)$ \\
\hline \multicolumn{5}{|l|}{ Targeted agents (\%) } \\
\hline $\begin{array}{l}\text { Tyrosine kinase } \\
\text { inhibitor }\end{array}$ & $149(80.1)$ & $70(72.2)$ & 0.1295 & $219(77.4)$ \\
\hline mTOR inhibitor & 37 (19.9) & $27(27.8)$ & & $64(22.6)$ \\
\hline \multicolumn{5}{|l|}{ Timing of treatment (\%) } \\
\hline First-line & 77 (41.4) & $43(44.3)$ & 0.6357 & $120(42.4)$ \\
\hline Second-line or later & $109(58.6)$ & $54(55.7)$ & & $163(57.6)$ \\
\hline \multicolumn{5}{|c|}{$\begin{array}{l}\text { CRP: C-reactive protein; ECOG: Eastern Cooperative Oncology Group; LDH: lactate } \\
\text { dehydrogenase; mRCC: metastatic renal cell carcinoma; NLR: neutrophil-to-lymphocyte } \\
\text { ratio; ULN: upper limits of normal. }\end{array}$} \\
\hline
\end{tabular}

extrapulmonary metastasis cases, disease progression was shown in 90 of 190 cases. The $50 \%$ PFS for the low NLR group ( 12 months) was significantly $(p=0.0001)$ better than that for the high NLR group (6.7 months), while there was no significant difference in PFS between them in other cases $(p=0.3457)$ (Fig. 3). Univariate analyses showed that several variables are significantly associated with PFS including histological findings, PS, prior nephrectomy, number of metastatic organs, timing of treatments, and pretreated NLR. Multivariate analyses revealed that pretreated NLR was an independent and the strongest prognostic factor for PFS in mRCC cases with extrapulmonary metastasis (Table 4).

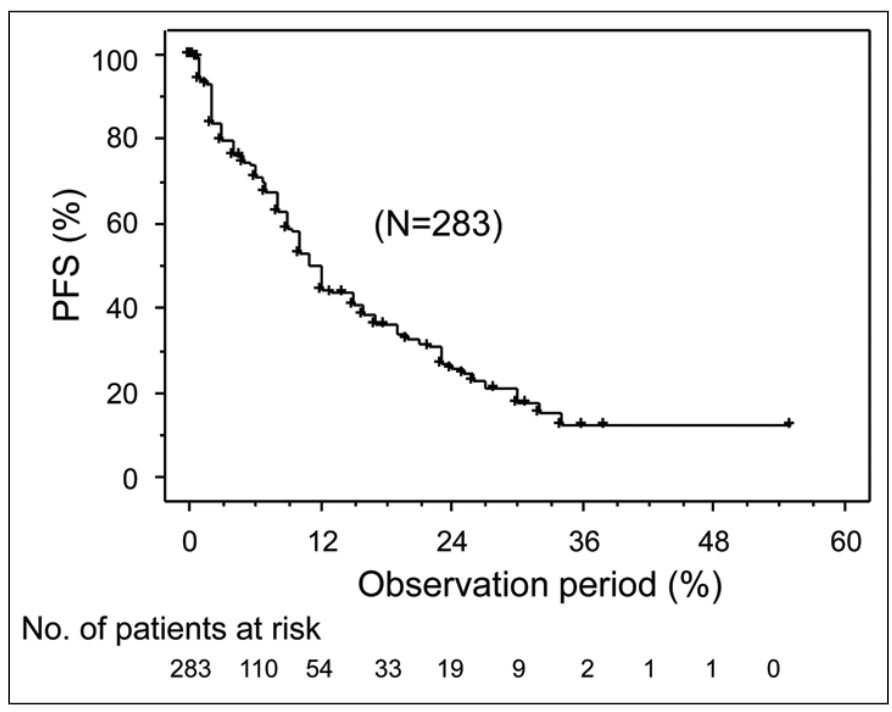

Fig. 1. Progression-free survival (PFS) for all cases.

\section{Discussion}

In this study, we demonstrated the impact of pretreatment NLR on predicting the response to targeted therapy in mRCC cases with extrapulmonary metastasis. To the best of our knowledge, the present study is the first report in which the significance of the pretreatment NLR differed depending on the metastatic organs in each case.

A previous study was focused on the significant implication of inflammatory response in the progression of mRCC. ${ }^{15}$ Patients with advanced RCC sometimes show paraneoplastic syndrome with fever and leukocytosis. The involvement of several molecules related to inflammation, such as interleukin- $6,{ }^{16}$ nuclear factor-kappa $B,{ }^{17}$ and $C R P,{ }^{10,11,13}$ on the progression of RCC have been previously demonstrated. A high NLR is associated with a poor prognosis in many solid tumours. ${ }^{14}$ We focused on the NLR as a biomarker candidate for the response for targeted therapy in cases of $\mathrm{mRCC}$. In the present study, high NLR was a predictive factor for poor PFS (Fig. 2, Table 2). These results were consistent with previous studies. ${ }^{14,18}$ However, as shown in Table 1, the characteristics of cases in the low NLR group were quite different compared with those in the high NLR group. The rate of cases involving risk factors such as anemia, higher $\mathrm{LDH}$, higher CRP, worse PS, and hypercalcemia in the high NLR group were higher than those in the low NLR group. In addition, the rate of extrapulmonary metastasis cases and that with two or more metastatic organs in the high NLR group were higher than those in the low NLR group, suggesting the possibility that the NLR is associated with metastatic status. Investigators have previously reported that systemic therapy, including targeted therapy and cytokine therapy, was expected to be effective in mRCC patients with lung metastasis. Cases with extrapulmonary metastasis were often resistant to these agents and showed poor prognosis. In retrospective studies, 
Teishima et al.

\begin{tabular}{|c|c|c|c|c|c|}
\hline & \multicolumn{2}{|c|}{ Univariate } & \multicolumn{3}{|c|}{ Multivariate } \\
\hline & HR & $\mathrm{p}$ & HR & $95 \% \mathrm{Cl}$ & $\mathrm{p}$ \\
\hline \multicolumn{6}{|l|}{ Age } \\
\hline$<65$ & reference & 0.3560 & & & \\
\hline$\geq 65$ & 1.175 & & & & \\
\hline \multicolumn{6}{|l|}{ Gender } \\
\hline Male & reference & 0.7668 & & & \\
\hline Female & 1.042 & & & & \\
\hline \multicolumn{6}{|l|}{ Histological findings } \\
\hline Non-clear & reference & 0.0002 & reference & & 0.0001 \\
\hline Clear & 0.391 & & 0.360 & $0.214-0.604$ & \\
\hline \multicolumn{6}{|c|}{ ECOG performance status } \\
\hline 0 & reference & $<0.0001$ & reference & & 0.0053 \\
\hline$\geq 1$ & 2.380 & & 1.905 & $1.210-2.997$ & \\
\hline \multicolumn{6}{|l|}{ Anemia } \\
\hline No & reference & 0.0130 & reference & & 0.3439 \\
\hline Yes & 1.574 & & 1.203 & $0.820-1.765$ & \\
\hline \multicolumn{6}{|l|}{ Hypercalcemia } \\
\hline No & reference & 0.0241 & reference & & 0.1817 \\
\hline Yes & 2.863 & & 1.905 & $0.740-4.905$ & \\
\hline \multicolumn{6}{|l|}{ High LDH } \\
\hline No & reference & 0.7207 & & & \\
\hline Yes & 1.162 & & & & \\
\hline \multicolumn{6}{|l|}{ Prior nephrectomy } \\
\hline No & reference & 0.0051 & reference & & 0.3259 \\
\hline Yes & 0.403 & & 0.703 & $0.348-1.420$ & \\
\hline \multicolumn{6}{|c|}{ No. of metastatic organs } \\
\hline$\geq 2$ & reference & 0.0032 & reference & & 0.0781 \\
\hline 1 & 0.588 & & 0.712 & $0.488-1.039$ & \\
\hline \multicolumn{6}{|l|}{ Targeted agent } \\
\hline TKI & reference & 0.0839 & & & \\
\hline mTORi & 1.459 & & & & \\
\hline \multicolumn{6}{|l|}{ Timing of treatment } \\
\hline First-line & reference & 0.0016 & reference & & 0.0014 \\
\hline Second-line or later & 1.814 & & 1.929 & $1.288-2.889$ & \\
\hline \multicolumn{6}{|l|}{ Pretreated NLR } \\
\hline$<3$ & reference & 0.0022 & reference & & 0.0014 \\
\hline$\geq 3$ & 1.769 & & 1.805 & $1.281-2.806$ & \\
\hline
\end{tabular}

bone metastasis was significantly associated with a poor PFS and overall survival (OS) in clear-cell mRCC patients treated with sunitinib ${ }^{19}$ and with everolimus after progression on vascular endothelial growth factor (VEGF)-targeted therapy. ${ }^{20}$ Liver metastasis was also associated with shorter PFS and OS treated with first-line sunitinib ${ }^{19}$ and was an independent risk factor for poor PFS and OS in cases treated with everolimus. ${ }^{20}$ In a review from the International Metastatic Renal Cell Carcinoma Database Consortium (IMDC), bone and liver metastases have been reported as predictive factors for poor prognosis. ${ }^{21}$ Brain metastasis in mRCC was associated with poor prognosis, but improved compared with that in the era of cytokine therapy. ${ }^{22}$ This evidence indicates the importance of considering the metastatic status in predicting the therapeutic effect in mRCC cases. Therefore, we focused on the relationship between the NLR and metastatic status. As a result, PFS in the low NLR group was significantly better than that in the high NLR group, and a high NLR was an independent predictive factor for worse PFS in the cases with extrapulmonary metastasis, while there was no significant difference in those of other cases (Fig. 3, Table 4). These data suggest that the impact of high NLR as an adverse predictive factor on the effects of targeted therapy is more predominant in $\mathrm{mRCC}$ cases with extrapulmonary metastasis 


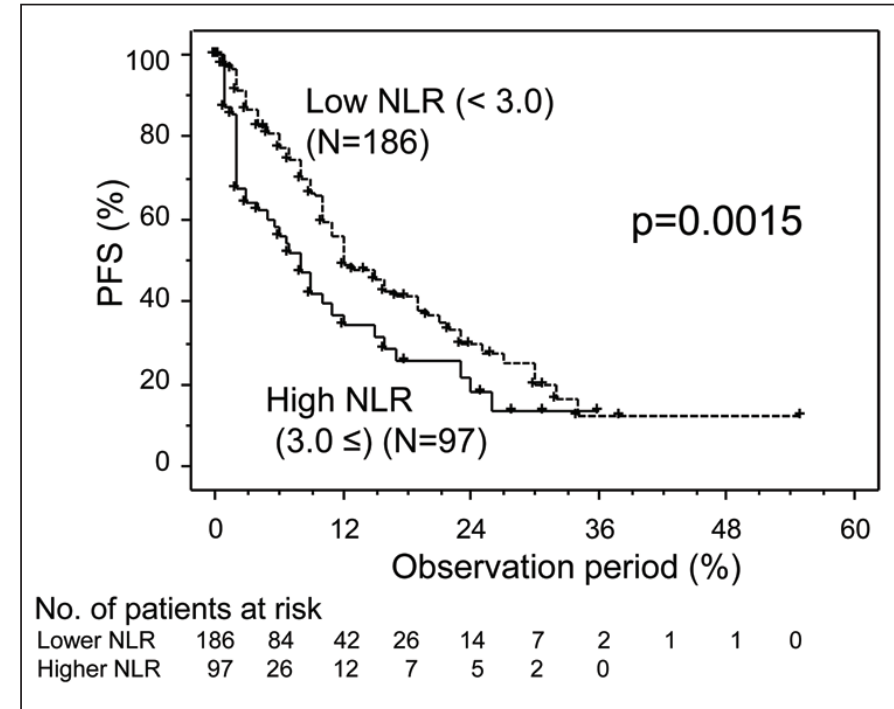

Fig. 2. Progression-free survival (PFS) for all cases of metastatic renal cell carcinoma (mRCC) involving targeted therapy further classified in accordance with neutrophil-to-lymphocyte ratio (NLR).

than in cases with only lung metastasis. Recent advances in targeted therapy for mRCC has led to the necessity to predict the therapeutic effect by taking the site of metastasis into consideration. The present data might provide us with meaningful information for targeted therapy in mRCC cases with extrapulmonary metastasis.

The limitations of this study are that it is retrospective and relatively small. In addition, medical conditions other than malignant diseases, which have been reported to be associated with NLR (such as hypertension, ${ }^{23}$ cardiovascular diseases, ${ }^{24,25}$ and diabetes ${ }^{26}$ ), were not able to be considered. Furthermore, the association of high NLR and poor outcome of cancer patients has not been sufficiently understood. One of the potential mechanisms of the impact of high NLR on the progression of malignant diseases including $\mathrm{mRCC}$ is the association with the inhibition of immune cells, such as lymphocytes, by neutrophils, and another is the association of the activity of neutrophils to secrete cytokines and growth factors that promotes tumour growth. ${ }^{14}$ Further study is required to clarify the mechanism of high NLR on the progression of cancers and to confirm the impact of the NLR for predicting the antitumour effect of targeted therapy in $\mathrm{mRCC}$ cases with extrapulmonary metastasis.

\section{Conclusion}

We demonstrated the significance of the NLR as one of the predictive factors in the response to molecular targeted therapy in mRCC cases with extrapulmonary metastasis. Since hematological tests are routinely conducted for patients with mRCC treated with targeted therapy, the NLR is easy to use in daily clinical practice. The establishment of a novel strategy is expected through the consideration of NLR as a biomarker.

Competing Interests: The authors report no competing personal or financial interests.

Acknowledgements: In addition to the authors, the following investigators participated in the study: Yuichi Kadonishi and Mitsuru Nakahara, Hiroshima Prefectural Hospital; Kenichiro Fukuoka, Shuntaro Koda, and Masanobu Shigeta, Kure Medical Centre; Yoshimasa Kurimura and Satoshi Maruyama; Hiroshima General Hospital; Hiroshi Masumoto and Seiij Fujïwara, Higashihiroshima

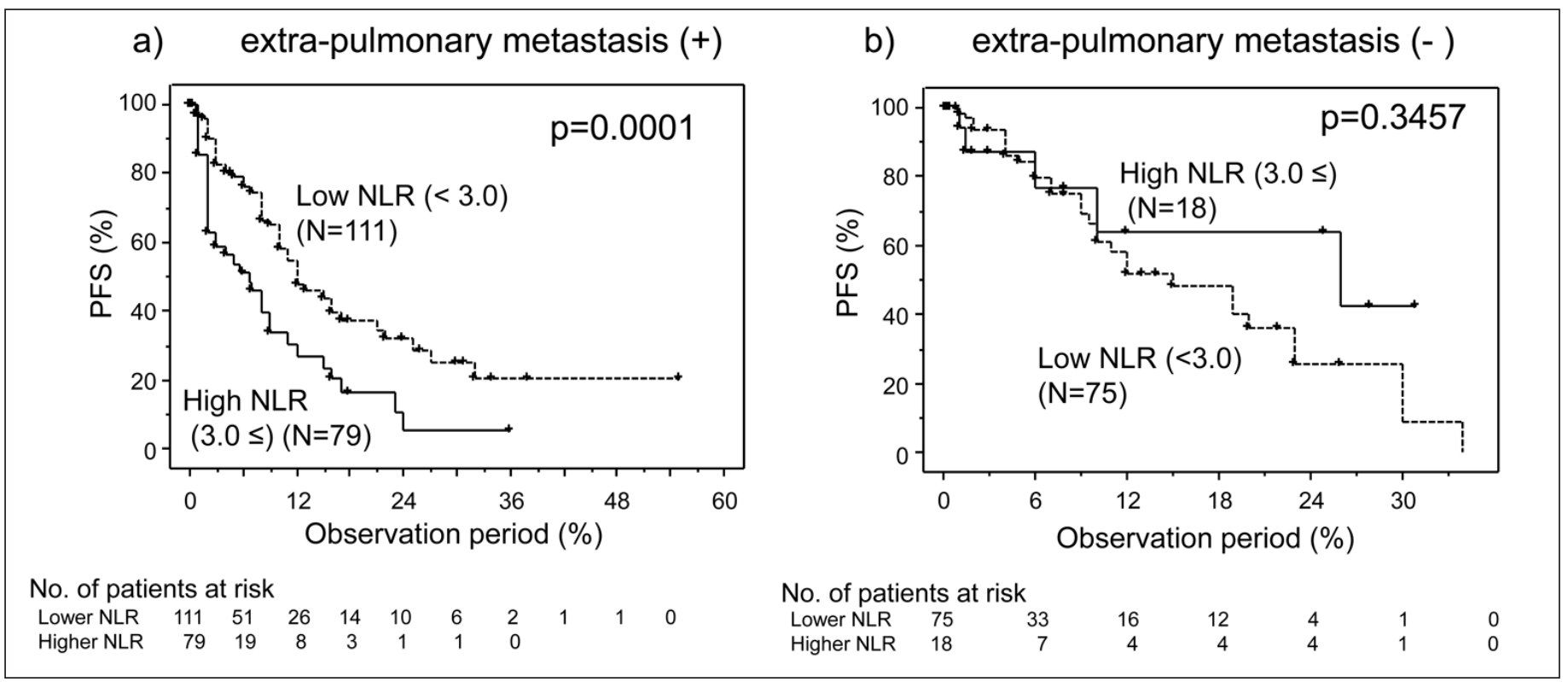

Fig. 3. Progression-free survival (PFS) for cases of metastatic renal cell carcinoma (mRCC) involving targeted therapy further classified in accordance with neutrophil-to-lymphocyte ratio (NLR) in cases of (a) extrapulmonary metastasis; and (b) those of no extrapulmonary metastasis. 
Teishima et al.

Table 3. Characteristics of mRCC cases of extrapulmonary metastasis involving molecular targeted therapy

\begin{tabular}{|c|c|c|c|c|}
\hline & \multicolumn{2}{|c|}{ Pretreated NLR } & \multirow[b]{2}{*}{$\mathbf{p}$} & \multirow[t]{2}{*}{ Total } \\
\hline & Low $(\leq 3.0)$ & High (>3.0) & & \\
\hline No. of patients & 111 & 79 & & 190 \\
\hline Age, range (median) & $40-85(64)$ & $47-85(67)$ & 0.0762 & $40-85(65)$ \\
\hline \multicolumn{5}{|l|}{ Gender, n (\%) } \\
\hline Male & $96(86.5)$ & $65(82.3)$ & 0.4267 & $161(84.7)$ \\
\hline Female & 15 (13.5) & $14(17.7)$ & & $29(15.3)$ \\
\hline \multicolumn{5}{|l|}{ Histological type, n (\%) } \\
\hline Clear & 92 (82.9) & $65(82.3)$ & 0.9137 & $157(82.6)$ \\
\hline Non-clear & $19(17.1)$ & $14(17.7)$ & & $33(17.4)$ \\
\hline \multicolumn{5}{|c|}{ ECOG performance status, $\mathrm{n}(\%)$} \\
\hline 0 & $87(78.4)$ & $57(72.2)$ & 0.3234 & $144(75.8)$ \\
\hline$\geq 1$ & $24(21.6)$ & $22(27.8)$ & & $46(24.2)$ \\
\hline \multicolumn{5}{|l|}{ Anemia, n (\%) } \\
\hline$(-)$ & $58(52.3)$ & $59(74.7)$ & 0.0017 & $117(61.6)$ \\
\hline$(+)$ & $53(47.7)$ & $20(25.3)$ & & $73(38.4)$ \\
\hline \multicolumn{5}{|l|}{ Hypercalcemia, n (\%) } \\
\hline$(-)$ & $109(98.2)$ & 71 (89.9) & 0.0113 & $180(94.7)$ \\
\hline$(+)$ & $2(1.8)$ & $8(10.1)$ & & $10(5.3)$ \\
\hline \multicolumn{5}{|l|}{ LDH (\%) } \\
\hline$\leq 1.5 \times$ ULN & $105(94.6)$ & $69(87.3)$ & 0.0760 & 174 (91.6) \\
\hline$>1.5 \times$ ULN & $6(5.4)$ & $10(12.7)$ & & $16(8.4)$ \\
\hline \multicolumn{5}{|c|}{ Metastatic organs, n (\%) } \\
\hline 1 & $41(36.9)$ & $26(32.9)$ & 0.5671 & $67(35.3)$ \\
\hline$\geq 2$ & $70(63.1)$ & $53(67.1)$ & & $123(64.7)$ \\
\hline \multicolumn{5}{|c|}{ Prior nephrectomy, n (\%) } \\
\hline Yes & $102(91.9)$ & $64(81.0)$ & 0.0261 & $166(87.4)$ \\
\hline No & $9(8.1)$ & $15(19.0)$ & & $24(12.6)$ \\
\hline \multicolumn{5}{|l|}{ Targeted agents, n (\%) } \\
\hline TKI & $85(76.6)$ & $57(72.2)$ & 0.4891 & $142(74.7)$ \\
\hline mTOR inhibitor & $26(23.4)$ & $22(27.8)$ & & $48(25.3)$ \\
\hline \multicolumn{5}{|c|}{ Timing of treatment, $\mathrm{n}(\%)$} \\
\hline First-line & $42(37.8)$ & $34(43.0)$ & 0.4708 & $76(40.0)$ \\
\hline Second-line or later & $69(62.2)$ & $45(57.0)$ & & $114(60.0)$ \\
\hline
\end{tabular}

ECOG: Eastern Cooperative Oncology Group; LDH: lactate dehydrogenase; mRCC: metastatic renal cell carcinoma; NLR: neutrophil-to-lymphocyte ratio; TKI: tyrosine kinase inhibitor; ULN: upper limits of normal.

Medical Centre; Tsuyoshi Ueno, Yasuhisa Hasegawa, and Masami Mizutani, Fukuyama Medical Centre; Tateki Yoshino, Mitsuru Kajiwara, and Hiroyuki Moriyama, Onomichi General Hospital; Hideki Mochizuki, Miyoshi Central Hospital.

This paper has been peer-reviewed.

\section{References}

1. Gupta K, Miller JD, Li JZ, et al. Epidemiologic and socioeconomic burden of metastatic renal cell carcinoma (mRCC): A literature review. Cancer Treat Rev 2008;34:193-205. htrps://doi.org/10.1016/i. ctrv.2007.12.001

2. Motzer RJ, Hutson TE, Tomzzak $P$, et al. Sunitinib vs. interferon alfa in metastatic renal cell carcinoma. N Engl J Med 2007;356:115-24. https://doi.org/10.1056/NEJMoa065044
3. Hudes $G$, Carducci $M$, Tomczak $P$, et al. Temsirolimus, interferon alfa, or both or advanced renal cell carcinoma. N Engl J Med 2007;356: 2271-81. https://doi.org/10.1056/NEJMoa066838

4. Motzer RJ, Escudier B, Oudard S, et al. Efficacy of everolimus in advanced renal cell carcinoma: A double-blind, randomized, placebo-controlled, phase 3 trial. Lancet 2007; 372:449-56. https://doi.org/10.1016/S0140-6736(08)61039-9

5. Escudier B, Eisen T, Stadler WM, et al. Sorafenib in advanced clear-cell renal cell carcinoma. N Engl J Med 2007;356:125-34. https://doi.org/10.1056/NEJMoa060655

6. Rini BI, Escudier B, Tomczak $P$, et al. Comparative effectiveness of axitinib vs. sorafenib in advanced renal cell carcinoma (AXIS): A randomized, phase 3 trial. Lancet 2011;378:1931-9. https://doi.org/10.1016/S0140-6736(11)61613-9

7. Motzer RJ, Hutson TE, Cella D, et al. Pazopanib vs. sunitinib in metastatic renal cell carcinoma. N Engl J Med 2013;369:722-31. https://doi.org/10.1056/NEJMoal303989

8. Grivennikov SI, Greten FR, Karin M. Immunity, inflammation, and cancer. Cell 2010; 140:883-99. https://doi.org/10.1016/i.eell.2010.01.025

9. Aggarwal BB, Gehlot P. Inflammation and cancer: How friendly is the relationship for cancer patients? Curr Opin Pharmacol 2009;9:351-69. https://doi.org/10.1016/i.coph.2009.06.020

10. Saito K, Kihara K. Role of C-reactive protein in urological cancers: A useful biomarker for predicting outcomes. Int J Urol 2013;20:161-71. hitps://doi.org/10.1111/j.1442-2042.2012.03121.x 


\begin{tabular}{|c|c|c|c|c|c|}
\hline & \multicolumn{2}{|c|}{ Univariate } & \multicolumn{3}{|c|}{ Multivariate } \\
\hline & HR & $\mathbf{p}$ & HR & $95 \% \mathrm{Cl}$ & $\mathbf{p}$ \\
\hline \multicolumn{6}{|l|}{ Age } \\
\hline$<65$ & reference & 0.6781 & & & \\
\hline$\geq 65$ & 1.092 & & & & \\
\hline \multicolumn{6}{|l|}{ Gender } \\
\hline Male & reference & 0.7756 & & & \\
\hline Female & 1.107 & & & & \\
\hline \multicolumn{6}{|l|}{ Histological findings } \\
\hline Non-clear & reference & 0.0003 & reference & & 0.0001 \\
\hline Clear & 0.378 & & 0.340 & $0.195-0.593$ & \\
\hline \multicolumn{6}{|c|}{ ECOG performance status } \\
\hline 0 & reference & 0.0003 & reference & & 0.0042 \\
\hline$\geq 1$ & 2.307 & & 2.065 & $1.257-3.393$ & \\
\hline \multicolumn{6}{|l|}{ Anemia } \\
\hline No & reference & 0.1287 & & & \\
\hline Yes & 1.391 & & & & \\
\hline \multicolumn{6}{|l|}{ Hypercalcemia } \\
\hline No & reference & 0.0714 & & & \\
\hline Yes & 2.338 & & & & \\
\hline \multicolumn{6}{|l|}{ High LDH } \\
\hline No & reference & 0.6896 & & & \\
\hline Yes & 1.203 & & & & \\
\hline \multicolumn{6}{|l|}{ Prior nephrectomy } \\
\hline No & reference & 0.0079 & reference & & 0.3156 \\
\hline Yes & 0.414 & & 0.692 & $0.338-1.420$ & \\
\hline \multicolumn{6}{|l|}{ No. of metastatic organs } \\
\hline$\geq 2$ & reference & 0.0220 & reference & & 0.0784 \\
\hline 1 & 0.582 & & 0.645 & $0.396-1.051$ & \\
\hline \multicolumn{6}{|l|}{ Targeted agent } \\
\hline TKI & reference & 0.1318 & & & \\
\hline mTORi & 1.451 & & & & \\
\hline \multicolumn{6}{|l|}{ Timing of treatment } \\
\hline First-line & reference & 0.0019 & reference & & 0.0004 \\
\hline Second-line or later & 2.016 & & 2.386 & $1.477-3.583$ & \\
\hline \multicolumn{6}{|l|}{ Pretreated NLR } \\
\hline$<3$ & reference & 0.0003 & reference & & $<0.0001$ \\
\hline$\geq 3$ & 2.192 & & 2.739 & $1.734-4.328$ & \\
\hline
\end{tabular}

11. Hu Q, Gou Y, Sun C, et al. The prognostic value of C-reactive protein in renal cell carcinoma: A systematic review and meta-analysis. Urol Oncol 2014;32:50.e1-8. https://doi.org/10.1016/i. urolonc.2013.07.016

12. Fuijta K, Inamoto T, Yamamoto Y, et al. Role of adjuvant chemotherapy for lymph node-positive upper tract urothelial carcinoma and the prognostic significance of C-reactive protein: A multi-institutional, retrospective study. Int I Urol 2015;22:1006-12. https://doi.org/10.1111/iju.12868

13. Teishima J, Kobatake K, Kitano $\mathrm{H}$, et al. The impact of change in serum C-reactive protein level on the prediction of effects of molecular targeted therapy in patients with metastatic renal cell carcinoma. BJU Int 2016;117:E67-74. https://doi.org/10.1111/biu.13260

14. Templeton AJ, McNamara MG, Šeruga B, et al. Prognostic role of neutrophil-to-lymphocyte ratio in solid tumours: A systematic review and meta-analysis. J Natl Cancer Inst 2014;106: dju124. https://doi.org/10.1093/inci/djul24

15. Hu K, Lou L, Ye J, et al. Prognostic role of the neutrophil-lymphocyte ratio in renal cell carcinoma: A meta-analysis. BMJ Open 2015;5:e006404. https://doi.org/10.1136/bmiopen-2014-006404
16. Blay JY, Rossi JF, Wiidenes J, et al. Role of interleukin-6 in the paraneoplastic inflammatory syndrome associated with renal-cell carcinoma. Int J Cancer 1997;72:424-30. https://doi.org/10.1002/ (SICI) 1097-0215(19970729)72:3<424::AID-IJC9>3.0.C0;2-R

17. Oya $M$, Takayanagi A, Horiguchi $A$, et al. Increased nuclear factorkappa $B$ activation is related to the tumour development of renal cell carcinoma. Carcinogenesis 2003;24:377-84. https://doi.org/10.1093/carcin/24.3.377

18. Zhang GM, Zhu Y, Gu WJ, et al. Pretreatment neutrophil-to-lymphocyte ratio predicts prognosis in patients with metastatic renal cell carcinoma receiving targeted therapy. Int I Clin Oncol 2016;21:373-8. https://doi.org/10.1007/s10147-015-0894-4

19. Beuselinck B, Oudard $S$, Rixe 0 , et al. Negative impact of bone metastasis on outcome in clear-cell renal cell carcinoma treated with sunitinib. Ann Oncol 201 1;22:794-800. https://doi.org/10.1093/ annonc/mdq554

20. Motzer RJ, Escudier B, Oudard S, et al. Phase 3 trial of everolimus for metastatic renal cell carcinoma: Final results and analysis of prognostic factors; RECORD-1 Study Group. Cancer 2010;116:4256-65. https://doi.org/10.1002/cncr.25219 
Teishima et al.

21. McKay RR, Kroeger N, Xie W, et al. Impact of bone and liver metastases on patients with renal cell carcinoma treated with targeted therapy. Eur Urol 2014; 65:577-84. https://doi.org/10.1016/i. eururo.2013.08.012

22. Bastos DA, Molina AM, Hatzoglou V, et al. Safety and efficacy of targeted therapy for renal cell carcinoma with brain metastasis. Clin Genitourin Cancer 2015;13:59-66. https://doi.org/10.1016/i.lgc.2014.06.002

23. Sun J, Ning H, Sun J, Qu X. Effect of hypertension on preoperative neutrophil-lymphocyte ratio evaluation of prognosis of renal cell carcinoma. Urol Oncol 2016;34:239.e9-239.e15. https://doi.org/10.1016/i. urolonc.2015.12.006

24. Avci A, Elnur A, Göksel A, et al. The relationship between neutrophil/lymphocyte ratio and calcific aortic stenosis. Echocardiography 2014;31:1031-5. https://doi.org/10.1111/echo.12534
25. Balta S, Demirkol S, Kucuk U, et al. The relationship between neutrophil-lymphocyte ratio and coronary collateral circulation. Perfusion 2014;29:367-8. https://doi.org/10.1177/0267659114538483

26. Lou $M$, Luo $P$, Tang $R$, et al. Relationship between neutrophil-lymphocyte ratio and insulin resistance in newly diagnosed type 2 diabetes mellitus patients. BMC Endocr Disord 2015;15:9. https://doi.org/10.1186/s12902-015-0002-9

Correspondence: Dr. Jun Teishima, Department of Urology, Institute of Biomedical and Health Sciences, Integrated Health Sciences, Hiroshima University, Hiroshim, Japan; teishima@hiroshima-u.ac.jp 